\title{
Familia y ley \\ Sobre La balada del regreso (I973), de Oscar Barney Finn
}

\author{
Malena Verardi \\ Facultad de Filosofía y Letras, UBA \\ CONICET \\ Marcela Visconti \\ Instituto Interdisciplinario de Estudios de Género \\ de la Facultad de Filosofía y Letras, UBA
}

\section{Resumen}

El presente artículo plantea un abordaje de la primera película realizada por Oscar Barney Finn, La balada del regreso (1973), un filme que ha sido poco explorado hasta la actualidad. En el trabajo se analizan las vinculaciones entre el contexto político en el que se inscribe la narración (los hechos posteriores a la batalla de Pavón, en I86I) y las relaciones interpersonales entre una familia tradicional del norte argentino y una patrulla militar que tiene orden de expropiar la finca familiar. De esta manera, lo público y lo privado se entrecruzan proponiendo una clave de lectura de un momento histórico significativo en cuanto a la construcción de la unidad nacional se refiere.

\section{Abstract}

This article presents an approach to the first movie made by Oscar Barney Finn, The Ballad of return (1973), a film that has been little studied to date. This paper analyzes
Palabras clave:

cine, historia, identidad, estética.

Keywords:

film, history, identity, aesthetics. 
the links between the political context in which the story takes place (events after the Battle of Pavón in 186I) and interpersonal relationships between a traditional family (that lives in northern Argentina) and a military patrol that is ordered to expropriate the family farm. Thus, public and private combine to suggest a key for reading an important historical moment in terms of building national unity.

\section{A modo de introducción}

El presente artículo plantea un abordaje de un filme que ha sido poco explorado hasta la actualidad. ${ }^{1}$ La balada del regre$s o,{ }^{2}$ primera película de Oscar Barney Finn, se filmó en la provincia de Salta durante 1973 y se estrenó el I 6 de mayo de 1974 en Buenos Aires, en la sala Ideal. Inscripta en un contexto sociohistórico de gran efervescencia política, formó parte de un grupo de películas que tomaban la historia argentina como eje narrativo, entre las cuales pueden mencionarse $L a$ Patagonia Rebelde (1974) de Héctor Olivera, Quebracho (1974) de Ricardo Wullicher, Juan Moreira (1973) de Leonardo Favio y Operación Masacre (1973) de Jorge Cedrón. Se trató de un período (entre el fin del gobierno militar de Onganía, el gobierno de Cámpora y la muerte de Perón) particularmente productivo en relación con la realización de filmes

1. El artículo es una versión de un trabajo más extenso, realizado en el año 2000, en el marco de la materia "Historia del Cine Argentino y Latinoamericano", de la Carrera de Artes (Facultad de Filosofía y Letras, UBA), cuyo titular era el profesor Claudio España. El abordaje del trabajo incluía una detallada entrevista a Oscar Barney Finn, así como un análisis de su historia como cineasta y de su obra fílmica, en particular de la película La balada del regreso. Partes de dicho trabajo fueron incorporadas por Barney Finn en un artículo de su autoría publicado en el número 43 de la Revista Espacios, en el año 2010, en una edición especial realizada con motivo del Bicentenario de la Revolución de Mayo, bajo el título: "Desandar lo andado".

2. La balada del regreso. Argentina. Año de realización: 1973. Dirección: Oscar Barney Finn. Guión: Oscar Barney Finn. Fotografía: Jorge Prats (en color-Eastmancolor). Música: Gustavo Beytelman. Ambientación y vestuario: Julia von Grolman. Producción ejecutiva: Julia von Grolman. Producciones Imperial. Distribución Cinetel. Duración: 90 minutos. Sala de estreno: Cine Ideal. Fecha de estreno: 16 de mayo de 1974. Intérpretes: Ernesto Bianco (Mayor Ocampo), María Luisa Robledo (doña Rosario), Julia von Grolman (Mercedes), Adrián Ghio (Martín), Hugo Arana (Teniente Pablo Arias), María Vaner (Sra. Figueroa), Elsa Daniel (Tomasa), Laura Palmucci (Juana), María José Demare (Manuela Ibañez) y otros. 